\title{
Creativity, Sociability, Solidarity New-Wave Carnival Krewes' Responses to COVID-19 in New Orleans
}

Martha Radice

Dalhousie University

\begin{abstract}
New Orleans was one of the first cities in the USA to be severely affected by the COVID-I9 pandemic. This article draws on long-term ethnography and recent remote fieldwork to explore how new-wave carnival krewes in New Orleans responded to the pandemic. New-wave krewes are one of the kinds of social clubs that produce carnival each year. During the first four months of the pandemic, some of them undertook various kinds of projects within their membership and in the broader community. I propose that these projects have three overlapping dimensions: creativity, sociability, and solidarity. My argument is that because they are so enmeshed in the social fabric of New Orleans, new-wave carnival krewes provided a solid foundation for social initiatives that sought to alleviate the existential and material insecurity of the pandemic. I further argue that carnival has emerged as an important way for New Orleanians to make the imaginative connection between the personal and the social that is necessary for grasping the scope of COVID-I9. More broadly, I contribute to what Joel Robbins has called an "anthropology of the good" in social relations.
\end{abstract}

Keywords: COVID-I9; carnival; New Orleans; creativity; sociability; solidarity; digital ethnography; anthropology of the good

Résumé: La Nouvelle-Orléans a été l'une des premières villes des États-Unis à être gravement touchée par la pandémie de COVID-I9. S'appuyant sur une ethnographie de longue durée et sur des études de terrain récentes à distance, cet article explore la manière dont les krewes new wave du carnaval de la Nouvelle-Orléans ont réagi à la pandémie. Les krewes new wave sont l'un des types d'associations qui organisent le carnaval chaque année. Au cours des quatre premiers mois de la pandémie, certains d'entre eux ont entrepris diverses sortes de projets impliquant leurs membres et la communauté élargie. Je suggère que ces projets comportent trois dimensions interreliées: la créativité, la sociabilité et la solidarité. Mon argument est que du fait de leur 
profonde imbrication dans le tissu social de la Nouvelle-Orléans, les krewes new wave ont fourni une base solide pour des initiatives sociales visant à atténuer l'insécurité existentielle et matérielle engendrée par la pandémie. Je soutiens en outre que le carnaval est apparu comme un moyen important pour les habitants de la Nouvelle-Orléans d'établir une connexion imaginative entre le personnel et le social, laquelle est nécessaire pour saisir la portée de la COVID-I9. Plus généralement, je contribue à ce que Joel Robbins a qualifié «d'anthropologie du bien» dans les relations sociales.

Mots-clés: COVID-I9; carnaval; Nouvelle-Orléans; créativité; sociabilité; solidarité; anthropologie du bien

ew Orleans was one of the first US cities to be severely affected by
COVID-I9, implementing measures to prevent its spread from mid-March 2020. From then on, new-wave carnival krewes, which are among the social clubs that organize the many practices of carnival in New Orleans, responded to the pandemic with diverse activities and projects. Continuing my ethnographic fieldwork in this milieu, I observed and sometimes participated in these responses from a distance. In this article, I propose that the responses have three main dimensions: creativity, sociability, and solidarity. New-wave krewes already engaged these themes in their pre-pandemic activities, but it was not obvious that they would continue to do so under the new circumstances, and the ways they did were novel. I argue that because they are so enmeshed in the social fabric of New Orleans, new-wave carnival krewes provided a robust foundation for social initiatives that seek to alleviate the existential and material insecurity of the pandemic. I also argue that carnival has emerged as an important way for New Orleanians to make the imaginative connection from the personal to the social that is needed to grasp the scope of COVID-I9. More broadly, I contribute to what Joel Robbins has called an "anthropology of the good" by "explor[ing] the ways [people] foster the good in their real social relations" (Robbins 2013, 458) in the time of COVID-19. Robbins identifies two other elements of "the good" that deserve anthropological attention: constructions of morality that underpin positive social relations and models of time and change that scaffold hope for the future. While I focus on social relations, traces of the other elements are also revealed in this study.

I begin by describing my broader ethnographic project. I then outline how the first four months of the pandemic unfolded in New Orleans. The core of the article explores in turn the creativity, sociability, and solidarity in new-wave 
carnival krewes' responses to COVID-I9. Finally, I discuss how ideas and images of carnival help connect the personal and the social as New Orleanians grapple with the pandemic.

\section{Researching Carnival in New Orleans}

Since 20I6, I have been undertaking an ethnography of new-wave carnival krewes in New Orleans. A "krewe" is a social club that puts on events during carnival season, which runs from Twelfth Night (6 January) to Mardi Gras (Fat Tuesday), 47 days before Easter Sunday. These events typically consist of a public parade and a private ball, although some krewes hold only one or the other. There are hundreds of carnival krewes and many ways that New Orleanians categorize them, according to their longevity, gender and racial composition, politics, social class, and aesthetics, among other variables. A key distinction is whether they make large parades with members riding floats pulled by tractors, or smaller parades with members walking alongside floats pulled by mules, bicycles, or humans. The larger-scale, mainstream krewes generally parade uptown, along Saint Charles Avenue, upriver of Canal Street. In contrast, the smaller-scale krewes can take to smaller streets in the Bywater and Marigny neighbourhoods and the French Quarter, downriver of Canal Street, so they are sometimes called "downtown" carnival krewes (Wade, Roberts and de Caro 2019). They have also been called "alternative" or "renegade" krewes (Hardy 2015, and in the 200I New Orleans Jazz and Heritage Festival), because their politics tend to be progressive and satirical, and their costumes, throws, and floats are handmade, not produced by New Orleans' professional carnival design industry. (A crucial feature of carnival parades, "throws" are trinkets, often beads, that paraders throw to spectators en route.) Evoking carnival history, I call these krewes "new-wave," since they emerged from the counter-cultural movements of the I960s-70s, over a century after the first float parade in I857, and they contrast with the most traditional "old-line" krewes as well as other mainstream krewes. New-wave krewes range in size: some stage their own parade while others are "subkrewes" of a bigger parade like Krewe du Vieux; some also roll in uptown parades. Of similar vintage and demographic composition, and sometimes grouped with new-wave krewes - indeed, several feature in this article are the troupes of women and men who appear between floats in uptown parades, dancing in the style of majorettes (Carrico 2013). New-wave krewes have proliferated in the 15 years since Hurricane Katrina, yet their scale and ethos hark back to the free-form street carnival that emerged in the early nineteenth century, well before float parades (Mardi Gras Unmasked LLC 2017; Gill 1997). 
New-wave krewes are only one element of carnival, which is a complex, lively field of cultural production (Kinser 1990; Mitchell 1995). Reflecting New Orleans society, carnival is socially stratified and relatively racially segregated. New-wave krewes tend to be made up of college-educated middle-class people, most of them white. Other social milieus sustain other carnival activities. African American traditions include the Mardi Gras Indians (Becker 20I3; Fi Yi Yi, Breunlin and Ehrenreich 2018; Lewis, Breunlin and Regis 2009; Lipsitz 1988), Baby Dolls (Vaz 2013), and Zulu Social Aid and Pleasure Club (F. Smith 2013). Gay carnival krewes have been creating spectacular tableaux at balls since the I950s, when it was not safe for them to parade (H. Smith 20I7; Wolff 2OII). Oldline krewes are for the white elite (Gill 1997). Some suburban white folks do "truck parades" (Roberts 2006). Individuals might belong to both dancing troupes and parading groups, or both mainstream and new-wave krewes. Many people celebrate carnival simply by gathering at home or in the streets with friends, family, and strangers, well-dressed but not costumed. Carnival is also influenced by other dimensions of New Orleans culture, like second line parades (Olsen 2012; Regis 1999). New Orleans' parading culture is certainly "intertextual" (Lazar 2015).

I have conducted fieldwork in New Orleans during all or part of each carnival season over four years (2016 to 2020) and on several other trips, for ten months in total. When I am not in New Orleans - and even when I am - my participant observation extends into social media, mostly Facebook and, to a lesser degree, Instagram. Like Horst and Miller (2012), I maintain that the so-called virtual world of social media is not separate from some "real" world; rather, it can only be understood in relation to the non-digital social milieus in which it is embedded. Facebook has become part of how I keep up with the field (Dalsgaard 2016). I learn about carnival and its urban context as I see what members of carnival-related Facebook groups post, what events are happening, and what my Facebook friends share. Carnival comes up in New Orleanian conversation on Facebook as frequently as in person. Social media became even more important to my research in 2020, when COVID-I9 cut short a planned six-month fieldwork trip (Radice 2020). After leaving New Orleans in midMarch, I followed the impact of and responses to the pandemic there through social and traditional media. I kept in touch with friends by phone, WhatsApp, and Zoom. I revised my research ethics protocol to include remote interviewing, and the interviews I conducted over the summer all touched on the pandemic. This article is based on this continued remote fieldwork. 
Social media, especially Facebook, are a complex amalgam of public and private. Although my Facebook friends know that I am an anthropologist researching carnival, their friends (who engage with their posts) may not. For this reason, I refer here only to social media material that was circulated from public posts, though these might be re-shared privately. I also draw on interviews and conversations, used with consent, and traditional media, though I accessed newspapers, magazines, and TV reports online and often initially via social media. ${ }^{1}$

\section{COVID-19 in New Orleans}

New Orleans was hit hard and fast by the novel coronavirus. Its first presumptive case of COVID-I9 was reported on 9 March. By I5 March, 74 cases had been confirmed, two of them resulting in deaths (Weinstein 2020). Used to stocking up and hunkering down for hurricanes, New Orleanians began to prepare for a new kind of "sheltering in place." After initially restricting public gathering places only, Mayor LaToya Cantrell implemented a mandate to "stay at home" except for essential activities on 20 March, three days before Governor John Bel Edwards' state-wide mandate (https://ready.nola.gov/incident/coronavirus/ safe-reopening/; https:/gov.louisiana.gov/home/). As expected, COVID-I9 cases continued to grow, to I834 cases and IOI deaths by 3I March. The daily increase of new cases peaked on 2 April at 878. However, this indicator dropped off quite quickly and did not surpass I47 from 20 April to date (I4 August).

Phase One of reopening, "Safest at home," began on I6 May. It allowed gatherings of a "household size," asked people to "Limit the number of people with whom you regularly come into contact to a small and consistent 'crew,"' and mandated masks or face coverings for activities in public (except for outdoor recreation with social distancing). On I3 June, the city moved to Phase Two, which retained masking and distancing guidelines but permitted indoor gatherings of up to 25 people and outdoor gatherings of 50 and reopened many businesses and public places at reduced capacity. At first, bars reopened, but a resurgence peaking at 146 new cases on 26 July led to their restriction and then closure by the end of the month. To date (I4 August), New Orleans has not yet moved to Phase Three of its four phases of reopening. Most activities I discuss in this article took place under the Stay Home Order and Phase One.

The impact of COVID-I9 was severe but, like elsewhere, uneven. Infection rates were much higher among African Americans, who make up 60 percent of the New Orleans population, than whites, accounting for nearly 88 percent 
of all deaths outside long-term care facilities (Weinstein and Plyer 2020). Early victims of COVID-I9 included important African American figures in carnival in New Orleans: among others, community leader and museum founder Ronald W. Lewis (Kurutz 2020), and eight members of the Zulu Social Aid and Pleasure Club (Villarosa and Harris 2020). At first, reports linked racial disparities to higher rates of underlying comorbidities (Karlin and Russell 2020), but later accounts pointed to African Americans' over-representation in frontline essential jobs such as retail and healthcare, and their greater likelihood than whites of living in multigenerational households (Weinstein and Plyer 2020). New Orleans as a whole is structurally vulnerable to exposure to COVID-I9 due to high rates of poverty, gentrification/airbnbification (leading to high housing cost burdens), incarceration, uneven access to high-quality healthcare and education, systemic racism, and overdependence on the tourist industry, which pushes millions of people through the city every year and puts many locals into high-contact service work (Losh and Plyer 2020 discuss some of these factors).

The biggest tourist attraction in New Orleans is carnival. In 2020, Mardi Gras day fell on 25 February, and carnival was quickly identified as a superspreading event for the coronavirus, since it brought in so many tourists to mingle closely with locals. For a few days at the end of March, New Orleans' per capita COVID-I9 death rate briefly outstripped New York City's, and national media turned their searchlights on the city to blame carnival for the spread of the disease and Mayor Cantrell for not cancelling it. Yet, as she retorted, no guidance had come from higher levels of government to do so and no city in North America cancelled mass events in February. While they recognized with some anxiety that carnival might have been a giant petri-dish for SARS-CoV-2, the people I learn from in New Orleans resisted the puritan overtones of the carnival-shaming narrative (Adams and Johnson 2020; Radice 2020). Moreover, carnival networks were to prove to be a source of diversion, comfort, and succour during the early months of the pandemic.

\section{Creativity}

Carnival season ends on Fat Tuesday, but New Orleans' calendar features many other parades. The first major events that Mayor Cantrell cancelled were the second line parades scheduled for 15 March, the parades for Saint Patrick's Day (I7 March), and the Mardi Gras Indian parades held around Saint Joseph's Day (I9 March) (WDSU Digital Team 2020). A few new-wave krewes that were due to parade around then created virtual alternatives. The first was the recently 


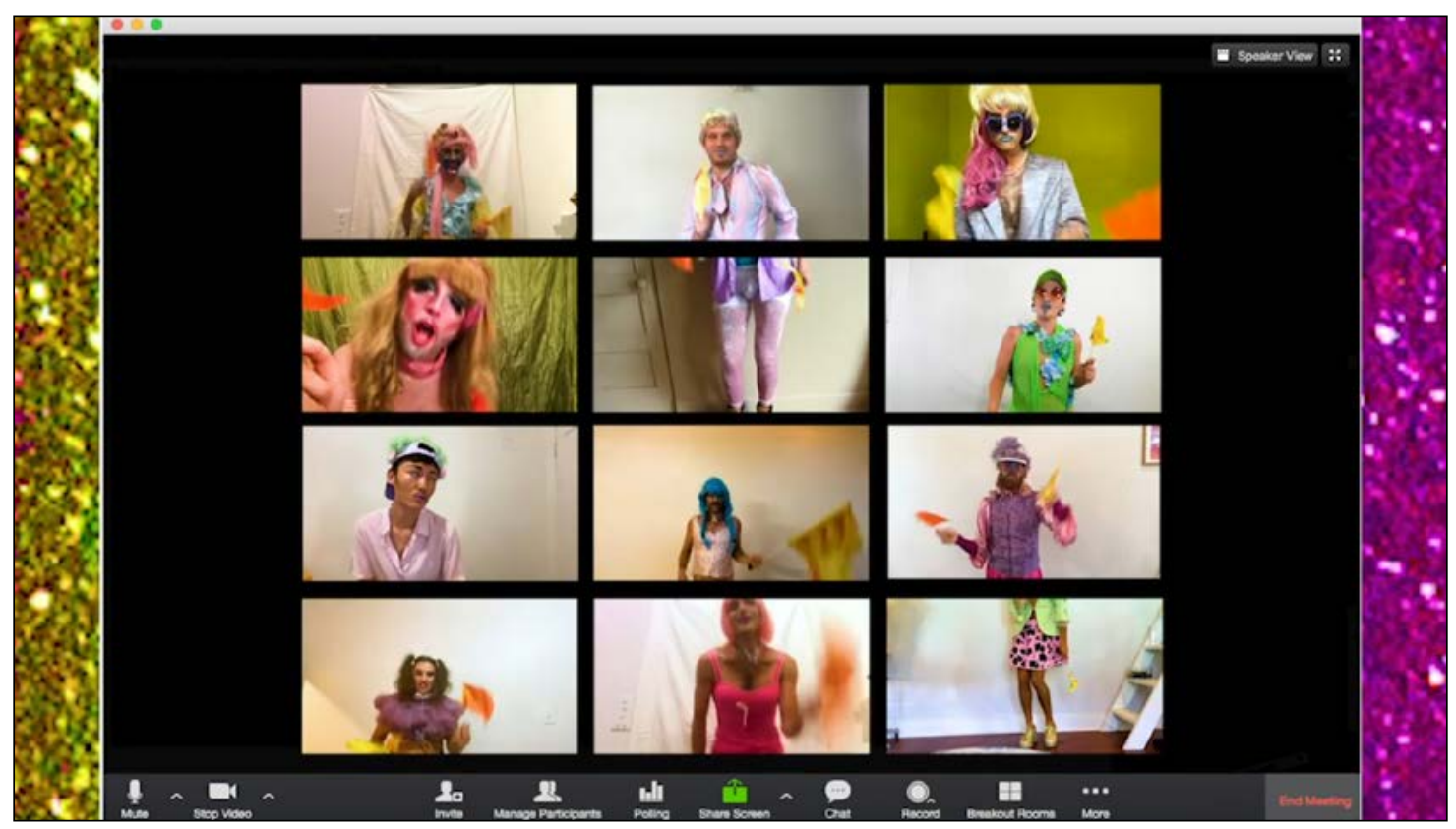

Figure 1: A screenshot of The Flaming Flagettes' virtual Easter parade video.

Source: James Page, https://vimeo.com/406725254

founded Krewe du Fool, which parades on April Fool's Day (I April). They invited participants to send photos or videos of themselves dressed in their Fool's costume, which they compiled into a five-minute "virtual parade" framed by comical scenes of an impatient spectator (https://youtu.be/-IrDnVpzrsA). The final moments thank the participants and "most importantly" all kinds of frontline workers, ending with the message, "Stay home and save lives."

A more technically sophisticated virtual parade was made by the Flaming Flagettes, a "drag flag dancing troupe" (https://www.instagram.com/flaming flagettes/) who were due to appear in the Gay Easter Parade on 12 April. Their six-and-a-half-minute video (https://vimeo.com/406725254) is a visual parody of the videoconferencing platform Zoom, which was widely adopted in North America as people sought to keep in touch under conditions of physical distancing. Twelve Flagettes appear in their little squares, mostly in 'speaker view' but sometimes in 'gallery view' and occasionally upside-down (Figure I). They wake up and transform into their flaming selves, in colourful wigs, make-up and costume, dancing with mini versions of their signature flame flags and lipsyncing to a medley of three songs. Their finale is, appropriately, Whitney Houston's "I wanna dance with somebody." The group announced, "This year, the Flagettes, like the rest of the world is stuck at home and cannot go out to look for the Easter bunny. The world needs joy and the world needs laughter, so the group has decided to do a virtual parade on a Zoom call!" (Clapp 2020). 
A similar creative activity that new-wave carnival krewes embraced has a scope far wider than New Orleans. As the curve-flattening "lockdown" was imposed, various groups used video-making apps to compile and share a kind of video that became known as the \#dontrushchallenge, after the soundtrack of the first version (Isama 2020), or the \#(passthe)brushchallenge, for reasons that will become clear. The "challenge" may refer to putting the video together or to one group challenging another to do so. Each video begins with a person dressed in ordinary clothes doing an everyday activity at home. The person is surprised by an object thrown to them from off-camera, often a make-up brush (hence the name). They brush the object against the camera lens, creating a moment of darkness from which they emerge, as if by magic, looking entirely different, in costume, regalia, or glamorous clothes. After posing for a few seconds, they throw their brush off-camera to the next person, keeping the direction consistent for ease of editing (so if they caught it from above, they drop it below).

According to Teen Vogue, the trend started with eight students who were stuck in their dorms as campuses shut down in response to the pandemic (Isama 2020). The friends were all women of colour, and the video challenge became particularly popular among Black and Indigenous women, who made these videos to celebrate their identity, strength, and collective beauty though they could not meet in person. I saw versions made by Inuit, Maaori, Sámi, Anishinaabe, Choctaw, Tongan, and Nigerian women and girls and African American women doctors. Other \#brushchallenge videos came from fantasy and cosplay fans, goths, and gender-non-conforming make-up artistes, among others. Video-making groups thus formed around shared ethnicity, profession, identity, hobby, or friendship to come together while apart and showcase their group's aesthetic.

The \#passthebrushchallenge seemed tailor-made for New Orleans' newwave carnival krewes. One krewe challenged another, which challenged another, creating a chain of eleven videos, while another krewe made a video without being challenged. ${ }^{2}$ In these videos, posted between I6 April and 29 May, the transition objects are usually a krewe-specific throw or costume element rather than a make-up brush (for instance, decorated $45 \mathrm{rpm}$ records for the Disco Amigos). Sometimes, the "everyday" segments are structured by the krewe's theme. The Krewe des Fleurs, who personalize costumes made from a basic design of one flower variety each year, from gilded lilies in 2015 to passion flowers in 2020, were filmed in backyards or parks. Many of the Rolling Elvi men who dress as Elvis Presley and ride motor scooters in several uptown 
parades - are seen polishing Elvis memorabilia or looking at Elvis records before they catch the krewe-branded poker chip and turn into the man himself. Their soundtrack is, naturally, Elvis.

The Krewe of Krampus took the \#passthebrushchallenge to new heights (https://youtu.be/G5_59YOlOa8). Founded in 2015, Krampus parades in early December, drawing on the Central European folk figure who threatens naughty children into being good just in time for the visit of Saint Nicholas on 6 December. Since Krampus is traditionally male, the Krewe invented the Sisters of Shhh as a female equivalent, a kind of ice queen who demands silence from carousing children. The video opens with an exasperated mother shouting at her rambunctious pillow-fighting children to be good, because "Krampus is watching!" Next, a woman holding a goat "hears" the mother. She metamorphoses into the Queen of the Sisters of Shhh and starts passing their signature snowflake throw from sister to sister, and then on to a series of folks who turn into horsey monsters and goat-like Krampuses, using cowbells as their transition objects. The final Über-Krampus passes a lump of golden coal to a man who becomes Saint Nicholas, wearing a protective mask over his white beard. The words "Be Kind - Take care of each other" float over him before the screen fades to black and "Krampus is Watching" appears.

This video has a narrative arc that other \#passthebrushchallenge videos lack. Krewe captain Michael Esordi explained:

Part of our whole thing with Krampus is storytelling. I watched a lot of the other videos that had been done [...] and sure they were interesting in terms of, visually, but [...] you could watch it from any point of the loop and it would be the same. I wanted ours to tell a story and tie into who we are as a krewe.

The video plays on light and dark: everyday members appear in daylight while their masked character emerges from the dark, mirroring their night-time parade. It ends, like the parade, with Saint Nicholas, a figure of reassurance after all the scary monsters. The video also tells a story of the pandemic:

Everyone was just going nuts at that time with kids being at home and not knowing what to do, couldn't go play with their friends so they were just acting out at home. [...] So we had that bit in the beginning that wasn't typical of those videos. And then the whole tie-in to the Queen of Shhh hearing it from a distance and calling all the Krampus to gear up and take care of the naughty kids. And then finally, again, just like our parade, 
finally with a voice of hope at the end, it's not all doom and gloom, Krampus will take care of the naughty but hey, there's hope, Saint Nicholas is here, [...] this is going to be all right. Be good, and we'll be good.

Another notable creative endeavour that emerged early in the pandemic was a public Facebook group called Covid Couture, started by Ashley Charbonnet. It was not tied to any carnival krewe, but its theme is central to carnival practices. Stuck at home after her workplace closed, Ashley told me she started wearing silly outfits around the house "just to get out of pyjamas," and figured that other people might be equally in need of sartorial stimulation. At first, the group shared photos of "quarantine looks" they were wearing or noticed on social media, but that led to "a lot of mask selfies," so Ashley started setting challenges with small cash prizes as incentives. The first was to create an outfit with garbage bags; the second, to create one with food packaging "to get some more texture and colours in there;" and the third was simply to take inspiration from "your quarantine life." Ashley judged each challenge and made elaborate awards ceremony videos to showcase all entries before announcing the winner. Feeling tired after the third one, she invited other people to take over. One woman set a challenge of dressing in a single colour, and a man set the ramen challenge, "to get all gussied up and then take pictures of yourself on the couch eating ramen noodles, because that's what we were all eating a lot of." Ashley recalled that this was the time when people were not even going out to grocery stores, and since many people's incomes had plummeted, instant ramen were the frugal choice.

Like the \#passthebrushchallenge, this type of creativity was not unique to New Orleans. In its resourcefulness, it resembled the trend of recreating famous paintings with whatever you have to hand at home, which was started independently by several individuals and museums in March and April (Bruner 2020). Covid Couture was also open to people from around the world. Yet it spread through local social networks and depended on skills that are well-honed in New Orleans. Ashley said:

I don't think that I created the only fashion group, I think there were other ones, even other ones called Covid Couture [...] in other places. But I do think that New Orleans does have a kind of a stronghold on costumery. [...] We have glitter in our make-up bags, and we have lots of wigs, and it's something that we have in our arsenal all the time. Certainly, I don't think we have a monopoly on costume, but I think we do it best! 
Participants in Covid Couture included Cree McCree and Oliver Manhattan, who each earn their living in part from making headpieces and costumes for carnival and other holidays. Cree drew on her own wardrobe and imagination to post many photos beyond the challenges, keeping her spirits up by dressing up. Oliver won the "quarantine life" challenge with her coronavirus wig, inspired by the famous red-and-grey image of SARS-CoV-2 made by the Centers for Disease Control and Prevention (Giaimo 2020) (see Figure 2). Manhattan's wig was a very carnivalesque contribution, being exactly the kind of parody of current events that one sees in new-wave carnival parades such as Krewe du Vieux.

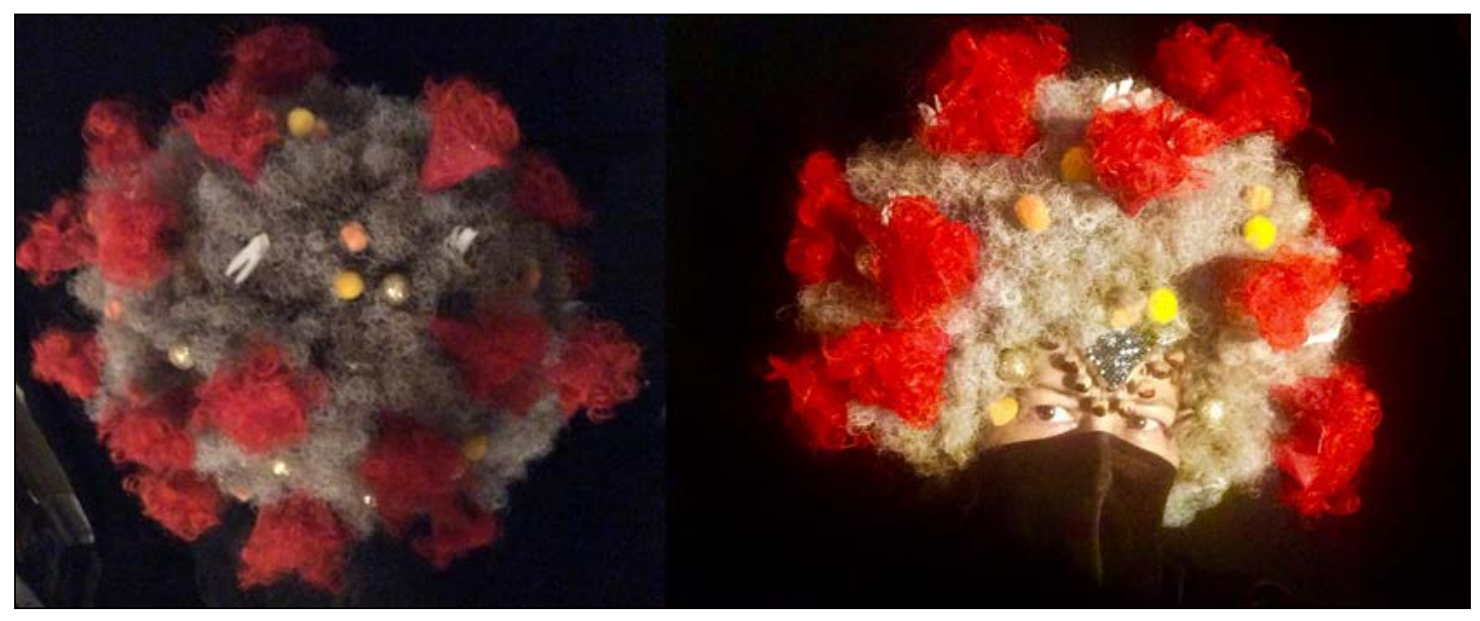

Figure 2: Oliver Manhattan's winning coronavirus wig (left), modelled by Oliver (right). "A local New Orleans Facebook group, Covid Couture, presented the challenge 'create a look from something in your quarantine.' I chose the virus itself." Source: Oliver Manhattan.

Creative endeavours like the ones I have described sprang up wherever people had access to the requisite technology during the pandemic. They gave people something to do, a creative outlet, a goal to meet within the confines of home. Collective projects gave people a reason to contact their friends. Toluwalase Asolo, who posted the first \#dontrushchallenge video, told Teen Vogue: "We understand that in a period like this with nothing to do, a lot of people may slip into depression due to high levels of inactivity and idleness.... So we decided to highlight the togetherness in isolation" (Isama 2020, n.p.). What was particularly New Orleanian about them, I suggest, was the critical mass of people who had not only the know-how to make and perform in costumes, but also the desire to do so regularly and be recognized for it. Costuming and performing are common habits in New Orleans; they form part of public culture and collective identity. The stay-home mandate imposed new conditions on these habits, but, as Michael Esordi put it, "Creative people are going to 
create." The carnival-related creations that emerged cheered up makers and audiences, providing some solace in a challenging time. Notably, some creations conveyed a public health message, whether explicitly (written messages) or implicitly (characters wearing protective masks). The collaboration these projects required points to a second way new-wave carnival krewes responded to the pandemic: finding novel formats for socializing.

\section{Sociability}

New-wave carnival krewes are vital hubs of sociability. People start them or join them with friends and/or make new friends through them. In February 2020, I attended the ball of the Krewe of Red Beans to admire their costumes decorated with beans and pulses. Asking why folks had joined the krewe, I heard the refrain "I felt like I found my people!" over and over. As well as firm friendships, satisfying, convivial acquaintanceships form in carnival krewes. Some members might not see each other from one carnival to the next, while smaller clusters might meet up weekly. Levels of sociability depend on the collective culture of the krewe and the extent of its year-round activities as well as the inclinations of individual members. Nonetheless, krewes are important social clubs. Like the "hidden" urban networks of amateur musicians studied by Finnegan (2007), they generate the full range of frequency and intensity of urban social ties.

Once public places like bars had closed under the Stay Home mandate, New Orleanians, like people in similar circumstances elsewhere, sought alternative, often virtual meeting spaces. For six Sundays from 29 March to 26 April, the science-fiction and fantasy themed Intergalactic Krewe of Chewbacchus held a Virtual Cocktail Hour via Zoom. With about 2,60o members in over a hundred sub-krewes, Chewbacchus is the largest walking krewe. Although Virtual Cocktail Hour participation was relatively small - I5 to 25 people in the two I attended - krewe co-captain (or Overlord, in krewe parlance) Aryanna Gamble told me that they were an important "mental health check-in" to find out how people were coping with the lockdown, and to offer practical help such as grocery delivery to anyone who needed it. People were happy to see each other as they swapped news and views of the unfolding pandemic. Some were in costume; others were stitching protective masks. Chewbacchus member Martin Childs told me that the Virtual Cocktail Hour was especially important after Brian Held, Jr., well-known as a champion of the krewe and host of the podcast The Week in Geek, passed away in March. At the Cocktail Hour following Held Jr.'s death, the krewe's slogan "Krewe love is true love" was deeply felt. 
Many new-wave carnival krewes organize events outside carnival season, to raise funds or membership for their own organization or others, to participate in events like Pride, to celebrate holidays, or simply to get together. Founded in I996 as a space for Jew-ish (emphasis on the "ish") folks to get involved in the very Catholic holiday of Mardi Gras, the Krewe du Jieux usually holds a Passover Seder at a member's home in New Orleans. This year, on 9 April, the Seder was held online; as each household ate its meal, the captain shared a scan of the krewe's Haggadah on her screen for participants to take turns reading aloud. Most people joined in from New Orleans, but some joined from other states. I joined from Halifax, Nova Scotia, missing the shared food but appreciating the connection and the memories it brought back of the Krewe du Jieux Seder of 20I6, as well as the few other Seders I have attended.

The Krewe of Krampus usually holds a "Krampus in July" event, riffing on the "Christmas in July" celebrations that take place around 25 July at campgrounds and other sites of popular culture. Krewe captain Michael Esordi's "love for mashing up opposites" turned it into a "German luau," a "combination of Alpine and Polynesian," as he told me. Held at a biergarten-style restaurant in the Bywater neighbourhood where Krampus parades, the ticketed event usually features a special menu, performances, and a costume contest, and serves as a membership drive as much as a social event. This year, as July approached, even though it looked like bars and restaurants might reopen, "we still weren't sure that we wanted to be responsible for bringing a bunch of people together physically." Michael talked to one of their regular dancers, who said that "all her gigs had been cancelled and her husband had lost his job." This made the krewe decide to hold Krampus in July as a virtual event. Four dancers, a burlesque artiste playing a "live mermaid," and a ukulele musician recorded videos which were mixed with live streams from a few locations where members had gathered in their household bubbles. The performers played for tips or for donations to Feed the Second Line (of which more later). Michael was pleased with how it went: "One of the biggest things we got, feedback-wise, were people either messaging us or in the comments of the event itself, saying how nice it was to have such a positive evening that they could gather round and plan for and stuff, during this time."

These social events, posted in public groups, were oriented inward, toward krewe members. As in pre-COVID times, not everyone will have participated. Those who did will have suffered the limitations of virtual sociability: the flattening of sounds that makes background chatter as loud as the main speaker 
and makes it hard to tell who has spoken, the time lag and screen freeze, the impossibility of side conversations, the ease with which people can leave without saying goodbye. They will have also enjoyed the advantages of virtual sociability: the novelty of seeing people's homes or virtual backgrounds, the chance for faraway friends to join in, the opportunity to multitask, the low bar for participation (no pressure to make small talk when only one person can speak at a time), the ease with which people can leave without saying goodbye. In these ways, new-wave carnival krewes were one of the social networks that members could turn to for valuable moments of sociability at a time of anxiety and isolation. They were also a source of solidarity, as the next section explains.

\section{Solidarity}

The urge to help others has been a widespread response to the COVID-I9 pandemic among new-wave carnival krewes, like elsewhere. Carnival may appear to be purely hedonistic, but many carnival krewes build altruism into their activities, donating money, labour, food, or materials to worthy causes. While old-line krewes have the capacity to set up charitable foundations, new-wave carnival krewes may hesitate between keeping scant funds raised or giving them away. But in a city that has powerful post-Katrina experience of what NGOs and volunteers can achieve, and in a country where philanthrocapitalism has edged out state support in both the public imagination and the resources available (Adams 20I3), the call to "give back" is strong and widely heeded. Posting publicly on Facebook on 26 March to promote Feed the Frontline (discussed below), carnival float designer Caroline Thomas attributed New Orleans' community response to COVID-I9 to parading culture:

We spend so much of our time out in the streets, socializing with friends and making new ones. We join krewes and spend our Saturday nights hot gluing together over a pot of beans or building some mini float in a friend's garage, learning the simple pleasure of coming together as a group to create something [...]. But krewes aren't just about the party.

The pandemic provided myriad opportunities to help fellow citizens. Although some initiatives were directed to healthcare - sewing and distributing homemade protective face-coverings, feeding frontline health workers - most seemed to be embedded in an analysis of the pandemic's economic consequences. The tourism industry on which New Orleans depends all but shut down, leaving thousands of waitstaff, bartenders, cooks, cleaners, housekeepers, guides, musicians, performers, and others unemployed. In the weeks ending 
2I March, 28 March, and 4 April, the Louisiana Workforce Commission processed I05,000 new unemployment insurance claims in the New Orleans metropolitan area (estimated population I,270,530 in 2019). The Accommodation and Food Services sector led the jump in new claims (Habans 2020). To put this in perspective, the previous week, only I,700 new claims had been submitted in all sectors state-wide (Bridges 2020). At $\$ 247$ a week, Louisiana unemployment insurance is the third lowest in the USA, and though it was supplemented by $\$ 600$ a week from the Federal Pandemic Unemployment Compensation, the latter was scheduled to end on 3I July. In short, many people were going or about to go without, and many others wanted to step up to help.

New-wave carnival krewes led several quite different aid initiatives. Some simply raised money. The Art of the Parade Society, an organization recently founded to unite and support walking krewes, invited krewes to submit designs for print-on-demand masks that members might purchase and wear. A portion of the \$16 price tag of each mask went to the Meals for Musicians program organized by the Howlin' Wolf music venue and the New Orleans Musicians' Clinic. By I8 July, \#BreatheArt had raised \$2,260 for this cause. The Krewe of 'Tit Rəx, which adopts the local children's tradition of making carnival floats from shoeboxes to hold a very small-scale parade, took a different approach. Recognizing that as service and creative workers, many members were in dire financial straits themselves, the Krewe's board gently invited members to donate if they could to Familias Unidas en Acción, which supports Latinx immigrant families (who are ineligible for government assistance if undocumented). Other krewes provided goods and labour directly. The Société des Champs Elysées, whose Twelfth Night "parade" is held on the new Rampart-St. Claude streetcar line that terminates at Elysian Fields Avenue, already ran the Sunday lunch kitchen at St Mark's United Methodist Church to feed 200 people five or six times a year as part of its solidarity work. During the first months of the pandemic, krewe members helped serve meals to 200-500 people a week, and joined a loose and eclectic food distribution coalition involving existing food banks and NGOs, a gay nightclub, councilmember Kristin Gisleson Palmer, restaurateurs, and several radical left organizations, among others. Working pragmatically, they aimed particularly to reach people who were homeless or immobilized in their homes who could not access or reheat meals provided by other organizations.

The Krewe of Red Beans has been the most visible carnival krewe undertaking solidarity work, due partly to its captain Devin De Wulf's media savvy. Annelies De Wulf, Devin's wife, is an emergency room doctor; her story early 
in the pandemic of the happiness that a gift of cookies brought to her shift's break-room one day inspired Devin to create Feed the Frontline NOLA. The organization bought meals at local restaurants and paid out-of-work musicians to deliver them to hospital workers throughout the city. It wrapped up on 3 May, having raised over a million dollars and provided nearly IoI,ooo meals (https:// www.feedthefrontlinenola.org/). It had been a challenge for it to expand so quickly, and as the first wave of cases waned, aid initiatives in general shifted away from the healthcare frontline to longer-haul poverty relief. The Krewe of Red Beans launched Feed the Second Line on 24 April. Its mission is "to provide food-love and employment to our culture-bearers - musicians, Mardi Gras Indians, Social Aid \& Pleasure Club members, artists, and other cultural figures in the New Orleans community" whose livelihoods and potentially lives are at risk from COVID-I9 (Krewe of Red Beans 2020). The term "culture-bearers" was popularized by public folklorists working in Louisiana, and "often refers to members of racialized cultural minorities who are identified as participants in a specific cultural practice" (Helen Regis, personal communication). In this context, it means people who sustain performance traditions rooted in New Orleans' African American community, like the jazz scene, Mardi Gras Indians and Baby Dolls, and the social aid and pleasure clubs that hold second line parades. It encompasses people who are paid for their culture-bearing work and those who are not; moreover, the idea of "bearing" culture signals intergenerational transmission. Feed the Second Line employed younger, more mobile culture-bearers to buy and deliver groceries, meals from local restaurants, and farmers' market produce to less mobile seniors. As of Io June, they had employed 38 people and fed 150 elders (De Wulf 2020). They also paid ten Mardi Gras Indians to create beadwork pieces, images of which would be transferred to merchandise such as $\mathrm{t}$-shirts to raise further funds.

Aid during the pandemic in New Orleans is not driven exclusively by carnival krewes. However, carnival is one scene where connections are made that facilitate solidarity. People whose social bonds are partly forged through carnival and public culture have come together to help each other in many ways. Rahn Broady, an educator and gardener, started what became a kind of informal food bank on his front porch, where people drop off and pick up whatever they can share. It began with fruit and vegetable seeds, starts, and produce, but the variety and sources of items multiplied as the porch became better known. People dropped off extras from their gardens, pantries, food bank packages, or volunteer work: cooked meals, canned goods, pet food, tampons, beans, rice, 
kombucha scobys, cleaning products, herbal tea, and more. Rahn posted about the porch publicly on Facebook, encouraging people to share widely, take only what they needed, prioritize the unemployed and immunocompromised, and start growing their own food too. The stable space and the large, diverse and partly carnival-connected social network that the frequent announcements reached meant that even though it was irregular, this casual system of mutual aid made a real difference in the neighbourhood.

The carnival connections that drive solidarity can be political in other ways. After police in Minneapolis murdered George Floyd on 25 May, the preoccupations of my social media feeds from New Orleans shifted from COVID-I9 relief to \#BlackLivesMatter (while maintaining the analytical link between the two, in light of the racial disparities outlined earlier). As protests gathered momentum, Julie Lea, captain of the city's largest mainstream carnival krewe, the allwomen, intentionally racially diverse Mystick Krewe of Nyx, posted that "all lives matter" on the krewe's Instagram feed. This caused immediate furore, sparking resignations of members, float lieutenants, and board members, and widespread calls for Lea to resign (MacCash 2020a; 2020b). Faced with a clear example of the current inflections of the politics of race in carnival culture, many new-wave krewes issued position statements supporting \#BlackLivesMatter, repudiating Lea's racism, and severing any ties with Nyx. For example, the Krewe des Fleurs announced that they had donated the $\$ \mathrm{I}, 000$ fee that they received for marching with Nyx in 2020 to the Backstreet Cultural Museum, which preserves African American cultural traditions (whose founder, Sylvester Francis, sadly passed away in September 2020). They invited "other compensated marching organizations and dance groups to join us in donating to Black artists, culture bearers, and change agents in and throughout New Orleans" (Krewe des Fleurs, open letter, I2 June 2020). The Nyx scandal deserves its own article, but it illustrates, first, the ways that carnival intersects today with the politics of race (the two have never not been intertwined (Gill I997; Roach 1993)), and second, the potential for solidarity that can come from reflecting on that intersection.

From raising funds to issuing position statements on systemic racism and white supremacy, new-wave carnival krewes have thus been among those taking action during the pandemic. Some actions might seem closer to "charity" than "solidarity," when they are more distant from beneficiaries and mediated by money (for instance, the \#BreatheArt mask sales). However, I am still inclined to file them generally under "solidarity." New Orleans is a medium-sized, convivial city where the social distance between haves and have-nots is not 
great, particularly among new-wave carnival krewes, whose members range from the materially comfortable (doctors, professors, lawyers) to the precarious (waitstaff, chefs, freelancers, artists). From their perspective, the devastation caused by the floods following Hurricane Katrina is in recent memory, the uneven distribution of the benefits of rebuilding is in stark evidence, and the city's dependence on the now-gutted tourist economy is common knowledge. A shared consciousness of precariousness therefore permeates new-wave carnival krewes' COVID-I9 relief initiatives, giving them a certain orientation toward social justice, if not always a clear agenda for achieving it. ${ }^{3}$

\section{Imagining Carnival in the Thick of COVID-19}

In this article, I have shown how new-wave carnival krewes responded to the first four months of the COVID-I9 pandemic, March to July 2020. They came up with outlets for creativity, platforms for sociability, and acts of solidarity. Not all krewes nor all members organized or participated in such activities. As elsewhere, the restrictions imposed by the pandemic led to an uneven distribution of free time: some people found themselves furloughed and at a loose end while others buckled under increased or more complex workloads at home, plus childcare responsibilities. People might not have had the time, material resources, or physical or emotional energy for such projects. It was draining for people to process and adjust to the unfolding crisis (especially, of course, if they or their loved ones became infected with COVID-I9). Krampus captain Michael Esordi explained that he had put his krewe-related activities on hold for a while:

It's distressing. I'm stressed out about work, I'm stressed out about and it's stuff out of my control. I feel like, had we all just participated in doing better, maybe school wouldn't be not opening up the way it should, and maybe we would be able to parade the way we've always wanted to. So I'm nervous. I put all these years and years of effort into building this krewe and trying to do something, and who knows what's going to happen with parades.

Michael's words propel us along the proverbial emotional roller-coaster of the pandemic, but also demonstrate that personal energy levels are bound up in worries about the collective capacity to flatten the curve. It is not possible to take full stock of COVID-I9 at the level of the individual; wherever we live, thinking through its spread, its prevention, and its consequences requires us to think at the level of communities and societies. In New Orleans, carnival is an important conduit for this reflection. 


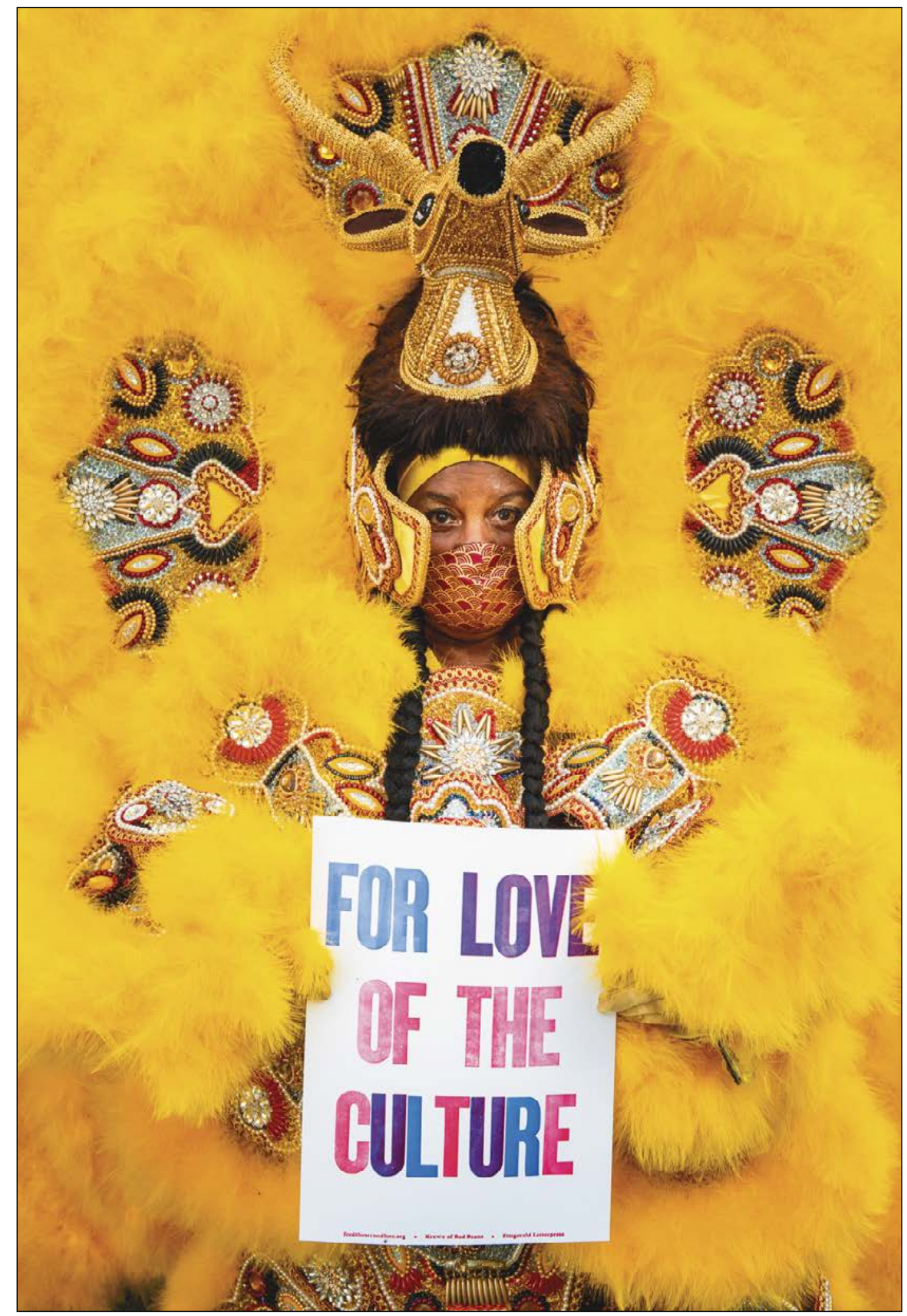

Figure 3: Queen Denice Smith of the Monogram Hunters in her 2020 suit on June 20, 2020, holding a poster for Feed the Second Line. Source: Ryan Hodgson-Rigsbee. 
The projects of creativity, sociability, and solidarity that I have discussed emerged from exceptional circumstances and they reflect this awareness of social relations. I have argued that because they are so tightly woven into the social fabric of New Orleans, new-wave carnival krewes made a solid springboard for projects that relieved some of the isolation and insecurity of the first months of the pandemic. The three dimensions of the activities overlap. Shared creative projects nourished sociability. Social ties reinforced solidarity. Creativity was put to the service of solidarity. Ryan Hodgson-Rigsbee, a New Orleansbased photographer I collaborate with, has been working to promote Feed the Second Line. On Instagram, he pairs photos of culture-bearers dressed up to parade with photos of them as they receive deliveries of groceries (Figure 3). In this way, he told me, a moment he had with Big Chief Pie of the Monogram Hunters wearing his Mardi Gras suit years ago is now achieving something he never imagined it would. "It feels more fulfilling than any newspaper article I've done. I'm definitely creating some positive change, instead of just throwing the photos up into the wind and hoping someone sees them and decides to be a better person." Ryan feels that his photos have a new layer of purpose:

For once in our life, we're not making normal new memories, so photography has a role in keeping us remembering our culture and our heritage and things like that, a reminder of what is worth fighting for. And helping give people a way to put their money into something to keep these people safe and alive.

Ryan enjoys visiting Mardi Gras Indians each week, and the appreciation, he says, is mutual: "Every single one of them is saying, this [Feed the Second Line NOLA] is amazing. [...] We see you." Solidarity thus forges new social bonds.

As time went on, inward-facing projects of creativity and sociability among new-wave carnival krewes petered out. I think this was partly because people got used to the "new normal," partly because meeting places began to reopen, and partly because other urgent matters came to the fore: campaigns for racial justice and for defunding the police, for the safe reopening of schools, and for the safeguarding of democratic elections in the USA. But New Orleanians' thoughts are also turning to carnival 202I. As I write (August 2020), no official word on whether parades will be permitted has come from the Mayor. Mainstream krewes are starting to prepare, though several are prudently omitting the year from designs so that throws could be saved for next year if need be (MacCash 2020c). Meanwhile, some new-wave krewes are hatching plans for events that could work safely within social distancing parameters. By the time 
this article is published, we will know more about how carnival unfolds during a pandemic.

Until then, carnival is a rallying point for New Orleanians. The NOLA Ready website for the City's Office of Homeland Security and Emergency Preparedness currently features a set of four photographs of people taking steps to "Prevent the spread of COVID-I9" (Figure 4). What is compelling about this imagery is that everyone is a figure from carnival. The upper left quadrant shows a Mardi Gras Indian, the Medicine Man of the 9th Ward Black Hatchet tribe, in his beautiful beaded suit, feathers radiating behind his face, around which he wears a disposable protective mask. His image is overlaid with the words "Wear a face covering in public." Upper right, a Black member of the Pussyfooters women's dance troupe, wearing their signature hot pink and tangerine corset, joyfully illustrates the instruction to "Wash hands often." Bottom left, a white woman from the Krewe of Merry Antoinettes wearing an I8th-century-style dress with side hoops (and a face mask) spreads her arms wide in an empty grocery store, making sure to "Stay six feet away from others."

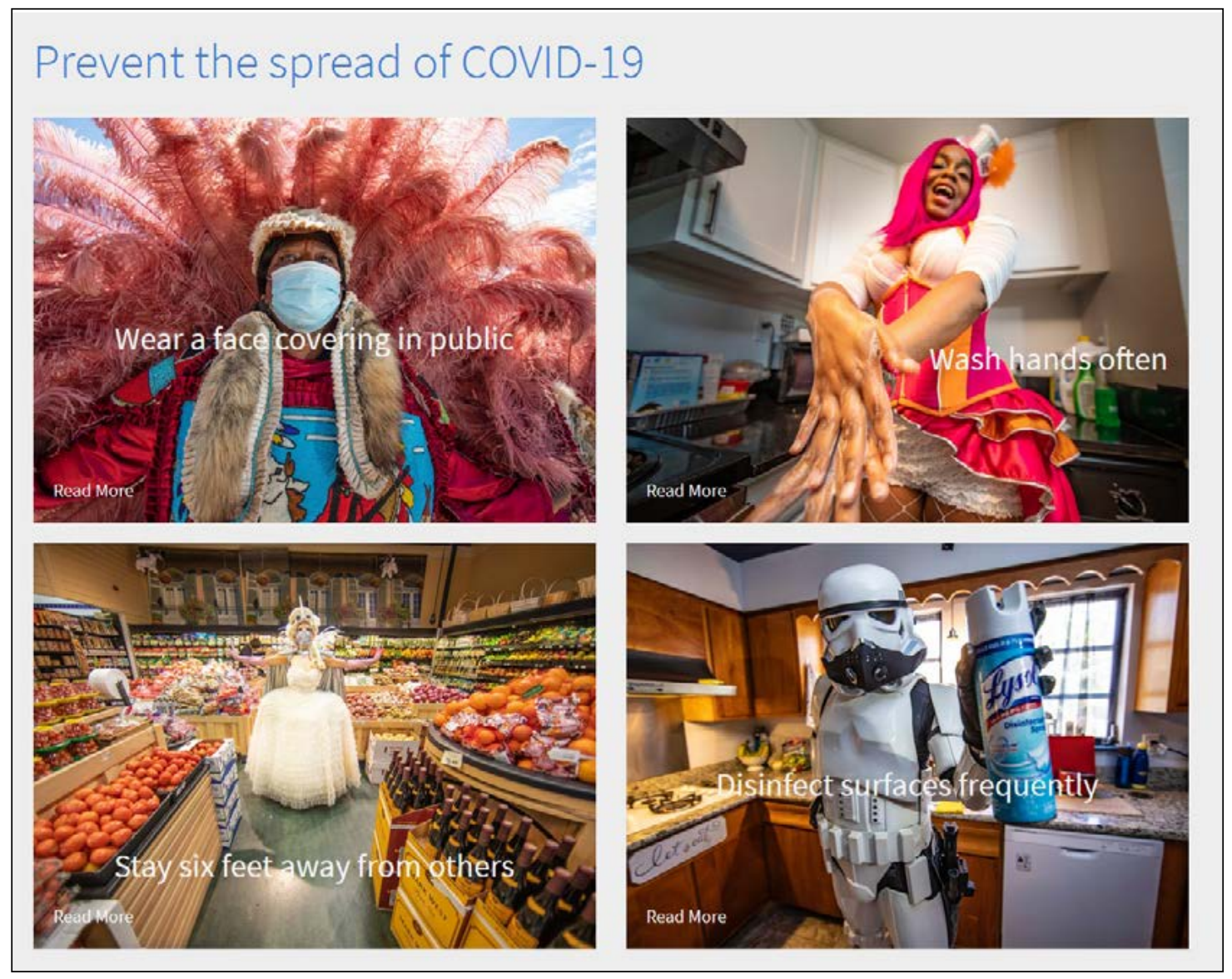

Figure 4: Carnival participants showing how to prevent the spread of COVID-19. Source: (C) Crista Rock, reproduced on https://ready.nola.gov/home/ 
Bottom right, a Star Wars Stormtrooper, recognizable in the New Orleans context as a member of the Intergalactic Krewe of Chewbacchus, brandishes a can of Lysol to tell us to "Disinfect surfaces frequently." All but the Mardi Gras Indian could be said to be part of new-wave carnival. All of them do carnival on foot, not on floats; crucially, as performer-participants they are on the same level as spectator-participants. Carnival, perhaps specifically walking carnival, has thus emerged in New Orleans as a way for people to make that imaginative leap from the personal to the social as they think, act, and live through COVID19. As another NOLA Ready poster instructs, using simple pictures, "Wear this [protective] mask now... so you can wear this [carnival] mask someday." In these images, we glimpse all three elements of Robbins' (2013) anthropology of the good: a construction of morality - the right thing to do - and a model of time - the cyclical ritual calendar - that complement the positive social relations new-wave carnival can foster. Carnival, a central cultural form that generates joy and structures "the good" in New Orleans, is a key referent as people take action together against "the bad" of COVID-I9.

\section{Martha Radice,}

Dalhousie University, martha.radice@dal.ca

\section{Acknowledgments}

I would like to express my heartfelt thanks to everyone who participated in research for this article, especially the people who generously granted interviews or contributed images. I am grateful to Alastair Parsons for his invaluable research assistance, and to Briana Kelly, Brenna Sobanski, and, above all, my accomplice Helen Regis for their insightful comments on earlier drafts. Any remaining errors of fact or interpretation are my own. Thank you also to the reviewers and editorial team of Anthropologica. I received a warm welcome from the New Orleans Center for the Gulf South at Tulane University as a visiting scholar in the first half of 2020. My research is funded by the Social Sciences and Humanities Research Council of Canada. Alastair Parsons' research assistance was funded by the Faculty of Arts and Social Sciences, Dalhousie University.

\section{Notes}

I No New Orleans newspapers are available through the databases to which my university library subscribes, which hinders systematic media review. 
2 The videos are by the Mermaids of the Sirens of New Orleans (April I6, https://www. facebook.com/SirensofNewOrleans/videos/33I400024489368/), Sailors of the Sirens of New Orleans (April I9, https://www.facebook.com/SirensofNewOrleans/videos/ 666737774158850/), Merry Antoinettes (April I9, https://www.facebook.com/themerry antoinettes/videos/53673493060oI7I/), Rolling Elvi (April 2I, https://www.facebook. com/rollingelvi/videos/55793II2I50I534/ and https://www.facebook.com/ watch/?v=577492706523239), Lucha Krewe (April 28, https://www.facebook.com/ luchakrewe/videos/369749930613799/), Disco Amigos (May 8, https://youtu.be/ 9hGkawaeyoU), Organ Grinders (May 29, https://youtu.be/lK5bC2DTrZQ), Dames de Perlage (April 26, https://www.facebook.com/DamesDePerlage/videos/ 545518906I49477/), Krewe des Fleurs (May 2, https://www.facebook.com/krewedes fleurs/videos/2478I2306579743/)Krewe of Krampus, May I8, https://youtu.be/ G5_59YOlOa8 ), and Intergalactic Krewe of Chewbacchus (May 28, https://www.face book.com/groups/chewbacchus/permalink/3507099709317287/).

3 I emphasize that this orientation is particular to this social milieu, not all New Orleanians or all carnival-makers.

\section{References}

Adams, Thomas J., and Cedric Johnson. 2020. "Austerity Is Fueling the COVID I9 Pandemic in New Orleans, Not Mardi Gras Culture." Jacobin. April. https://jaco binmag.com/2020/04/new-orleans-coronavirus-crisis-health-care-privatization.

Adams, Vincanne. 2013. Markets of Sorrow, Labors of Faith: New Orleans in the Wake of Katrina. Durham, NC: Duke University Press.

Becker, Cynthia. 2013. "New Orleans Mardi Gras Indians: Mediating Racial Politics from the Backstreets to Main Street." African Arts 46 (2): 36-49. https://doi.org/IO.II62/ AFAR_a_ooo64.

Bridges, Tyler. 2020. "Jobless Claims Skyrocket as Coronavirus Spreads through Louisiana's Economy." The Times-Picayune: Web Edition. I9 March. Accessed August 13, 2020. https://www.nola.com/news/coronavirus/article_03852830-6a32IIea-b2a9-07fc4259d274.html.

Bruner, Raisa. 2020. "How People Imitating Masterful Paintings Launched a Sweeping Trend From Italy to Iceland." TIME. Io April. https://time.com/5817II7/ coronavirus-art-history/.

Carrico, Rachel. 2013. "On Thieves, Spiritless Bodies, and Creole Soul: Dancing through the Streets of New Orleans." TDR/The Drama Review 57 (I (2I7)): 70-87. https://doi. org/IO.II62/DRAM_a_00235. 
Clapp, Jake. 2020. "New Orleans Drag Flag Dancing Troupe Flaming Flagettes Have a Virtual Easter Parade in New Video." Gambit. I2 April. https://www.nola.com/ gambit/news/the_latest/article_6aIIccd8-7do2-IIea-a6I6-e36e63367c3d.html.

Dalsgaard, Steffen. 2016. "The Ethnographic Use of Facebook in Everyday Life." Anthropological Forum 26 (I): 96-II4. https://doi.org/Io.I080/oo664677.2016.II480II.

De Wulf, Devin. 2020. "Letter to Editor on New Orleans' COVID i9 Feeding Initiative." The Lens. Io June. Accessed August I4, 2020. https:/thelensnola.org/2020/o6/10/ letter-to-editor-on-new-orleans-covid-I9-feeding-initiative/.

Fi Yi Yi, Committee Members of, Rachel Breunlin, and Jeffrey David Ehrenreich. 2018. Fire in the Hole: The Spirit Work of Fi Yi Yi and the Mandingo Warriors. New Orleans: Neighborhood Story Project, University of New Orleans Press, and the Backstreet Cultural Museum.

Finnegan, Ruth. 2007. The Hidden Musicians: Music-Making in an English Town. Middletown, CT: Wesleyan University Press.

Giaimo, Cara. 2020. "The Spiky Blob Seen Around the World.” New York Times. I April. https://www.nytimes.com/2020/o4/oI/health/coronavirus-illustration-cdc.html.

Gill, James. 1997. Lords of Misrule: Mardi Gras and the Politics of Race in New Orleans. Jackson: University Press of Mississippi.

Habans, Robert. 2020. COVID ig Economic Analysis. New Orleans: The Data Center. https://www.datacenterresearch.org/covid\%2OI9-data-and-information/covid\%2O I9-economic-analysis/.

Hardy, Arthur. 2015. "Alternative Krewes Have Long Been Part of Mardi Gras in New Orleans.” The Advocate. I7 February. Accessed May 30, 2020. https://www.nola. com/news/article_47edo58o-8b48-5317-b6cf-d66bf7441954.html.

Isama, Antoinette. 2020. "The Real Reason the \#DontRushChallenge Was Created." Teen Vogue. 7 April. https://www.teenvogue.com/story/dont-rush-challengecreator.

Karlin, Sam, and Gordon Russell. 2020. "Coronavirus Disparity in Louisiana: About $70 \%$ of the Victims are Black, but Why?" The Times-Picayune: Web Edition. 6 April. Accessed August 13, 2020. https://www.nola.com/news/coronavirus/article d804d4IO-7852-IIea-ac6d-470ebb6Ic694.html

Kinser, Sam. 1990. Carnival, American Style: Mardi Gras at New Orleans and Mobile. Chicago: University of Chicago Press. 
Krewe of Red Beans. 2020. "Press Release: Krewe of Red Beans, Rouses Markets, the Preservation Hall Foundation, Market Umbrella and the New Orleans Musicians' Clinic \& Assistance Foundation to Partner for Feed the Second Line Program." 23 April. Accessed August I4, 2020. https://www.feedthesecondline.org/about.

Kurutz, Steven. 2020. “Ronald W. Lewis, 68.” New York Times, BI4.

Lazar, Sian. 20I5. ““This Is Not a Parade, It's a Protest March”: Intertextuality, Citation, and Political Action on the Streets of Bolivia and Argentina." American Anthropologist II7 (2): 242-256. https://doi.org/IO.IIII/aman.I2227.

Lewis, Ronald W., Rachel Breunlin, and Helen A. Regis. 2009. The House of Dance and Feathers: A Museum by Ronald W. Lewis. New Orleans: University of New Orleans Press/Neighborhood Story Project.

Lipsitz, George. 1988. "Mardi Gras Indians: Carnival and Counter-Narrative in Black New Orleans." Cultural Critique I0: 99-I2I. https://doi.orgIo.2307/I354IO9.

Losh, Jenna, and Allison Plyer. 2020. Demographics of New Orleans and early COVID I9 Hot Spots in the U.S. LA: The Data Center New Orleans. https://www.datacenter research.org/covid \%20I9-data-and-information/demographic-data/.

MacCash, Doug. 2020a. "27 Nyx Float Lieutenants Quit after Captain Refuses to Step Down over 'All Lives Matter' Post.” The Times-Picayune: Web Edition. 8 June. Accessed August I4, 2020. https://www.nola.com/news/article_5f49a2Oa-a9fI-IIeaa384-67453488ea63.html.

—_ 2020b. "Nyx Mardi Gras Krewe Members Resign, Plan Protest after Captain's 'All Lives Matter' Post.” The Times-Picayune: Web Edition. 5 June. Accessed August I4, 2020. https://www.nola.com/news/article_63fiıIfo-a742-IIea-8eec-73965dieaIab. html.

Mardi Gras Unmasked LLC. 20I7. “Mardi Gras History.” Accessed August I5, 2020. https://mardigrastraditions.com/\#(Mardi_Gras_Traditions|filter)=.Mardi_ Gras_IOI;.

Miller, Daniel, and Heather A. Horst. 2012. "The Digital and the Human: A Prospectus for Digital Anthropology." In Digital Anthropology, edited by Heather A. Horst and Daniel Miller, 3-35. London: Bloomsbury.

Mitchell, Reid. 1995. All on a Mardi Gras Day. Cambridge: Harvard University Press.

Olsen, Margaret M. 20I2. "The Gift of the New Orleans Second Line.” In Neoliberalism and Global Theatres: Performance Permutations, edited by Lara D. Nielsen and Patricia Ybarra, I76-I88. London: Palgrave Macmillan. 
Radice, Martha. 2020. "Doing/Undoing/Redoing Carnival in New Orleans in the Time of COVID I9." Culture I4 (I). https://cascacultureblog.wordpress.com/2020/04/20/ doing-undoing-redoing-carnival-in-new-orleans-in-the-time-of-covid-I9/.

Regis, Helen A. 1999. "Second Lines, Minstrelsy, and the Contested Landscapes of New Orleans Afro-Creole Festivals." Cultural Anthropology I4 (4): 472-504. https://doi. org/IO.I525/can.I999.I4.4.472.

Roach, Joseph. 1993. "Carnival and the Law in New Orleans." TDR: The Drama Review (I988-) 37 (3): 42-75. https://doi.org/I0.2307/II463IO.

Robbins, Joel. 2013. "Beyond the Suffering Subject: Toward an Anthropology of the Good." Journal of the Royal Anthropological Institute I9 (3): 447-462. https://doi. org/IO.IIII/I467-9655.I2044.

Roberts, Robin. 2006. "New Orleans Mardi Gras and Gender in Three Krewes: Rex, the Truck Parades, and Muses." Western Folklore 65 (3): 303-328. https://doi. org/I0.2307/25474792.

Smith, Felipe. 20I3. “Things You'd Imagine Zulu Tribes to Do': The Zulu Parade in New Orleans Carnival." African Arts 46 (2): 22-35. https://doi.org/IO.II62/AFAR_a_0oo63.

Smith, Howard Philips. 20I7. Unveiling the Muse: The Lost History of Gay Carnival in New Orleans. Jackson: University of Mississippi Press.

Vaz, Kim Marie. 20I3. The "Baby Dolls": Breaking the Race and Gender Barriers of the New Orleans Mardi Gras Tradition. Baton Rouge: Louisiana State University Press.

Villarosa, Linda, and Kasimu L. Harris. 2020. “A Terrible Price': The Deadly Racial Disparities of Covid 19 in America." The New York Times Magazine. https://www. nytimes.com/2020/o4/29/magazine/racial-disparities-covid-I9.html.

Wade, Leslie A., Robin Roberts, and Frank de Caro. 20I9. Downtown Mardi Gras: New Carnival Practices in Post-Katrina New Orleans. Jackson: University Press of Mississippi.

WDSU Digital Team. 2020. "New Orleans St. Patrick’s Parades, Super Sunday, Large Events Canceled Because of Coronavirus Concerns.” WDSU6 TV. https://www. wdsu.com/article/new-orleans-st-patricks-parades-super-sunday-large-eventscanceled-because-of-coronavirus-concerns/31365373.

Weinstein, Rachel. 2020. Monitoring the COVID I9 Pandemic in New Orleans and Louisiana. New Orleans: The Data Center. https://www.datacenterresearch.org/covid \%20 I9-data-and-information/covid \%20I9-data/. 
Weinstein, Rachel, and Allison Plyer. 2020. Detailed Data Sheds New Light on Racial Disparities in COVID I9 Deaths. New Orleans: The Data Center. https://www.data centerresearch.org/reports_analysis/lack-of-data-obscures-true-levels-of-racialinequity-in-covid-deaths/.

Wolf, Tim. 20II. The Sons of Tennessee Williams. Documentary film. Directed by Tim Wolff. Produced by First Run Features. 